\title{
The Effects of Power Control on Free-Space Optical Communications during Snowfall and Rainfall
}

\author{
Salem Salamah, Muhammad A. Alsubaie, Mubarak Alhajri, Mahmoud Alnaser, \\ Ahmed Mohamed Abdalla
}

Department of Electronic Engineering Technology, Public Authority of Applied Education and Training, Adailiyah, Kuwait Email: Sh.salamah@paaet.edu.kw, ma.alsubaie@paaet.edu.kw, mk.alhajri@paaet.edu.kw, mj.alnaser@paaet.edu.kw, am.mahmoud@paaet.edu.kw

How to cite this paper: Salamah, S., Alsubaie, M.A., Alhajri, M., Alnaser, M. and Abdalla, A.M. (2018) The Effects of Power Control on Free-Space Optical Communications during Snowfall and Rainfall. Int. J. Communications, Network and System Sciences, 11, 216-227.

https://doi.org/10.4236/ijcns.2018.1110013

Received: September 29, 2018

Accepted: October 27, 2018

Published: October 30, 2018

Copyright (C) 2018 by authors and Scientific Research Publishing Inc. This work is licensed under the Creative Commons Attribution International License (CC BY 4.0).

http://creativecommons.org/licenses/by/4.0/

\begin{abstract}
Free-space optical (FSO) communication requires a line-of-sight connection between a transmitter and a receiver in which the information signal is modulated by an optical carrier that propagates in free space. The FSO channel is greatly affected by weather conditions such as fog, rain, and snow. In the literature, several adaptive techniques, such as power control (PC), have been suggested to mitigate channel link degradations. In this paper, we investigate the effects of snow and rain attenuation on the bit error rate (BER) of the FSO system using two types of modulations, the on-off keying (OOK) modulation and the pulse-position modulation (16-PPM). The effect of PC on the performance of FSO communications is also examined in this study. We evaluated the system's performance with two types of snow, wet snow and dry snow, as well as with different rain regions. Results show that PC improves the BER of the FSO system; a high rate of improvement is found for wet snow and rain. PC has almost no effect with dry snow because of the high attenuation and the limitations on transmitted power. The BER for 16-PPM is better than that for OOK modulation.
\end{abstract}

\section{Keywords}

Free Space Optical Communications, Snow Attenuation, Rain Attenuation, Power Control

\section{Introduction}

The increasing demand for high-speed Internet and high-capacity services has resulted in great pressure on communication systems and technologies. This has 
prompted researchers to seek solutions, including Free-space optical (FSO) communications technology. FSO communication is a line-of-sight technology that transmits an information signal by laser light through an atmospheric channel instead of fiber cables. It has several advantages, such as a license-free spectrum, large bandwidth, high data rate, easy installation, high security, and low power requirements [1] [2].

In general, the FSO system supports a binary modulation format such as on-off keying (OOK) modulation owing to its high-power efficiency and simplicity. OOK modulation is deployed with intensity modulation with direct detection; in the transmitter, the electrical signal is converted to an optical signal by modulating the intensity of a laser source using the OOK modulation scheme. At the receiving end, a photodiode converts the optical intensities into the corresponding photocurrent. The PPM scheme is another popular modulation format used in FSO systems; it is more power efficient than OOK modulation but has less band width efficiency and increased demodulation complexity. However, the FSO link performance and availability, as well as the link range, is highly dependent on the weather and atmospheric conditions. FSO wireless channels are adversely affected by different atmospheric conditions, such as fog, heavy rain, snow, dust, and haze; they increase the power loss and cause the BER to deteriorate. In order to mitigate fading of the channel, several parameters can be varied at the transmitter, such as the type of modulation, power, coding rate, and combinations of adaptation parameters. In one study [3], the author looked at the effect of snow attenuation on the transmission of FSO communications at different wavelengths without finding even a suggestion of a solution for alleviating the problem. In another study [4], the authors applied a PC algorithm to reduce the average power consumption; they regulated the transmitter gain from the erbium doped fiber amplifier given channel state information, but they did not study its effect on the BER of the system.

In [5] we are studying the FSO system using selective diversity to compensate for rain attenuation. Results show that selective diversity can improve the BER for high rain rates. Our contribution in this paper will come from our study of the effect of PC on the performance of an FSO channel during snow or rain attenuation using two different modulation techniques.

The rest of the paper is organized as follows: In Section II, the system model is described. In Section III, the results are presented for the two scenarios and for different types of modulations, and the effect of PC is also presented. In Section IV, conclusions are drawn.

\section{System Model}

We are studying an FSO system with a link channel that functions during several types of weather conditions, such as snow and rain. The snow particles are midway in size between the fog particles and the rain particles. Therefore, the level of attenuation due to snow is between the levels due to rain or fog. The level is 
higher than with rain but lower than with fog. In this case, the attenuation is comparable to that of fog and ranges between 30 and $350 \mathrm{~dB} / \mathrm{km}$. This level can significantly reduce the link availability of the FSO system [6].

\section{- Snow Attenuation:}

Snow attenuation varies according to whether the snow is dry or wet. The effect of dry snow is different than the effect of wet snow on the quality and strength of the received signal. Dry snow affects a channel when the rate of snowfall is low, whereas wet snow appears to affect a channel when the rate of snowfall is high. The attenuation is determined at a defined distance and measured in $\mathrm{dB} / \mathrm{km}$. The specific attenuation, or $\alpha_{\text {snow }}$ for snow rate $S$ in $\mathrm{mm} / \mathrm{h}$ is given as follows [7]:

$$
\alpha_{\text {snow }}=a S^{b}
$$

where the values of parameters $a$ and $b$ in dry and wet snow are

Dry snow: $a=5.42 \times 10^{-5} \lambda+5.49, b=1.38$,

Wet snow: $a=1.02 \times 10^{-4} \lambda+3.78, b=0.72$.

\section{- Rain Attenuation:}

Specific attenuation due to precipitation is observed in the optical and infrared ranges. It can be referred as rain attenuation and measured in $\mathrm{dB} / \mathrm{km}$. In FSO system, rain attenuation is particularly severe and greatly dependent on various models of raindrop-size distribution. The most commonly used raindrop-size distributions have been proposed by Marshal and Palmer [8]. The specific attenuation due to rain for a wireless optical link is given by

$$
\gamma(\mathrm{dB} / \mathrm{km})=a \cdot R^{b}
$$

where $R$ is the rain rate in $\mathrm{mm} / \mathrm{h}, a$ and $b$ are power law parameters. These parameters depend on frequency, raindrop-size distribution, and rain temperature. Due to the assumption that raindrops have a spherical shape $a$ and $b$ are independent of polarization [9]. The modeling of rain attenuation prediction is done using empirical methods proposed by the International Telecommunication Union Radio communication Sector (ITU-R) for FSO communications. The specific rain attenuation $\gamma(\mathrm{dB} / \mathrm{km})$ for an FSO link is delineated in the studies given by [10] [11] [12].

$$
\gamma(\mathrm{dB} / \mathrm{km})=1.076 \cdot R^{0.67}
$$

Carbonneau's model proposed values to predict $a$ and $b$ based on measurements done in France [13]. The measurements were for very low rain intensities compared with the rain intensities in tropical regions, however. In the study by [11] the author gives the rainfall rate, $R_{p}(\mathrm{~mm} / \mathrm{h})$, exceeded for a given percentage of the average year, $p$, and for any location. In this study, we will focus on rain regions in Canada, as shown in Table 1.

In FSO communications, the received power, $P_{r}$ has the following expression:

$$
P_{r}=P_{t} \tau_{t x} \tau_{r x} \frac{D^{2}}{(\theta L)^{2}} 10^{\frac{-\alpha_{\text {snow }} L}{10}}
$$


Table 1. Rain rates in Canada.

\begin{tabular}{cc}
\hline Canada Rain Regions & Rain Rate $(\mathrm{mm} / \mathrm{h})$ \\
\hline B & 12 \\
C & 15 \\
E & 22 \\
\hline
\end{tabular}

where $P_{t}$ is the transmitted power, $\tau_{t x}$ and $\tau_{r x}$ are the transmitter and receiver efficiency, respectively, $D$ is the receiver diameter, $\theta$ is the divergence angle, and $L$ is the link distance.

The signal-to-noise ratio (SNR) for the optical communications system using an avalanche photodiode (APD) detector is

$$
\mathrm{SNR}=\frac{\left(R_{0} P_{r} M\right)^{2}}{2 q B M^{x+2}\left(R_{0} P_{r}+I_{D}\right)+2 q I_{L} B+4 k T B F / R_{e q}}
$$

where $R_{0}$ denotes the primary sensitivity of the APD, $M$ is the APD gain, $x$ is the excess noise factor, $I_{D}$ is the bulk dark current, $I_{L}$ is the surface leakage current, $q$ is the electron charge, $k$ is the Boltzmann constant, $B$ is the equivalent noise bandwidth, $R_{e q}$ is the equivalent circuit resistance, $F$ is the noise figure, and $T$ is the system temperature in kelvins.

The measured SNR is compared with the desired level $\left(\gamma_{t h}=30 \mathrm{~dB}\right)$. The difference between these two values is quantized by the power command decision, and a power command is transmitted to the user through the feedback channel.

$$
\begin{gathered}
P_{i+1}=P_{i}-C \cdot \Delta \\
C= \begin{cases}-1 & \text { if } \gamma \leq \gamma_{t h} \\
1 & \text { if } \gamma>\gamma_{t h}\end{cases}
\end{gathered}
$$

where $C$ is the PC command and $\Delta$ is the step size [14].

The performance of the FSO system will be measured by the BER for two types of modulation, OOK modulation and N-PPM, as shown below [15]

$$
\begin{gathered}
\mathrm{BER}_{\mathrm{OOK}}=\frac{1}{2} \operatorname{erfc}\left(\frac{1}{2 \sqrt{2}} \sqrt{\mathrm{SNR}}\right) \\
\mathrm{BER}_{\mathrm{N}-\mathrm{PPM}}=\frac{1}{2} \operatorname{erfc}\left(\frac{1}{2 \sqrt{2}} \sqrt{\mathrm{SNR} \cdot \frac{N}{2} \cdot \log _{2}(N)}\right)
\end{gathered}
$$

\section{Simulation Results}

In this section, we will study the effects of PC on an FSO system in two weather conditions: snow and rain. Also, we will evaluate the performance of the FSO system using different types of modulation techniques. The parameters assumed in this simulation are shown in Table 2.

Figure 1 shows the rain and snow attenuation for two types of snow at different rates in $\mathrm{mm} / \mathrm{h}$. Dry snow has a higher attenuation than wet snow for all snow rates. Also, we noticed that snow attenuation is higher than rain attenuation 


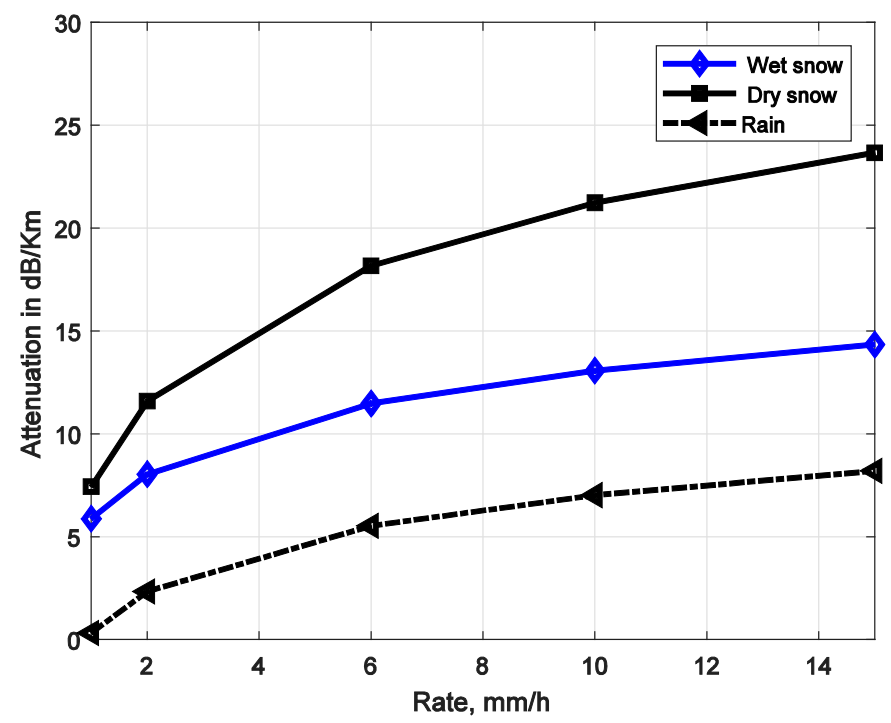

Figure 1. Snow and rain attenuation for different rates.

Table 2. Simulation parameters.

\begin{tabular}{cc}
\hline Parameters & Value \\
Wavelength & $850 \mathrm{~nm}$ \\
Transmitter power & $50-100 \mathrm{mw}$ \\
Transmitter divergence angle & $2 \mathrm{mrad}$ \\
$T X / R x$ efficiency & 0.5 \\
Receiver diameter & $0.1 \mathrm{~m}$ \\
Bulk dark current & $0.05 \mathrm{nA}$ \\
APD gain & 100 \\
PC step size & $5 \mathrm{mw}$ \\
Excess noise factor & 0.5 \\
Bandwidth & $25 \mathrm{MHz}$
\end{tabular}

due to the large size of snow particles. For example, at a rate of $10 \mathrm{~mm} / \mathrm{h}$, wet snow attenuation is more than rain attenuation by $6 \mathrm{~dB}$.

We compared the received power versus the link distance for wet snow with and without attenuation, as shown in Figures 2(a)-(c). The effect of the PC was also studied. In Figure 2(a) and Figure 2(b), one can see that wet snow attenuation can reduce the received power by $15 \mathrm{dBm}$ at a link distance of $1 \mathrm{~km}$. Figure 2 (c) shows that using PC has no effect on the received power for a low snow rate of $1 \mathrm{~mm} / \mathrm{h}$, but with a high snow rate, PC has more of an effect on thereceived power, especially with an increased link distance.

Figure 3(a) and Figure 3(b), and Figure 3(c) shows the SNR with and without PC during wet snow for two snowfall rates of $1 \mathrm{~mm} / \mathrm{h}$ and $6 \mathrm{~mm} / \mathrm{h}$. Using PC improves the SNR for a rate of $6 \mathrm{~mm} / \mathrm{h}$, but it has no effect on a low snow rate of $1 \mathrm{~mm} / \mathrm{h}$. The improvement is obvious after a link distance of $0.4 \mathrm{~km}$ and 


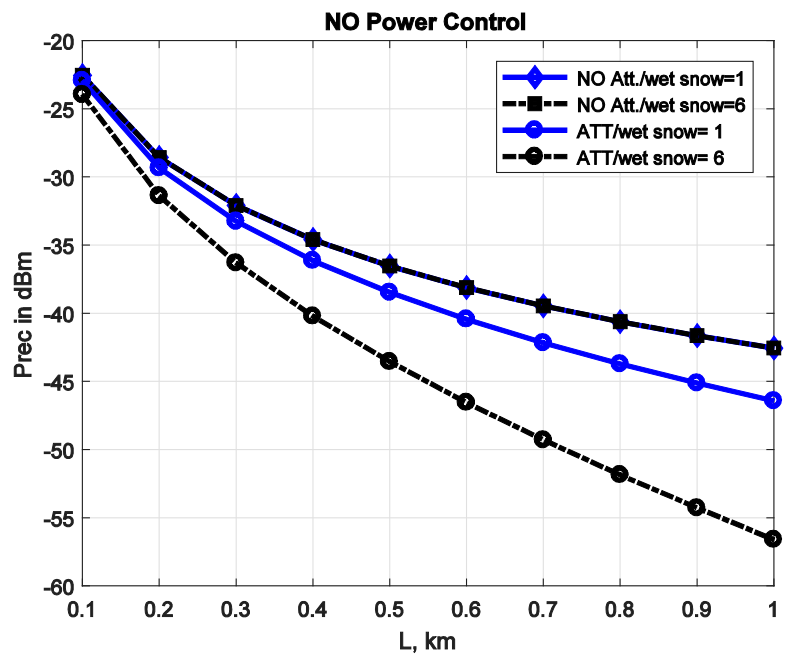

(a)

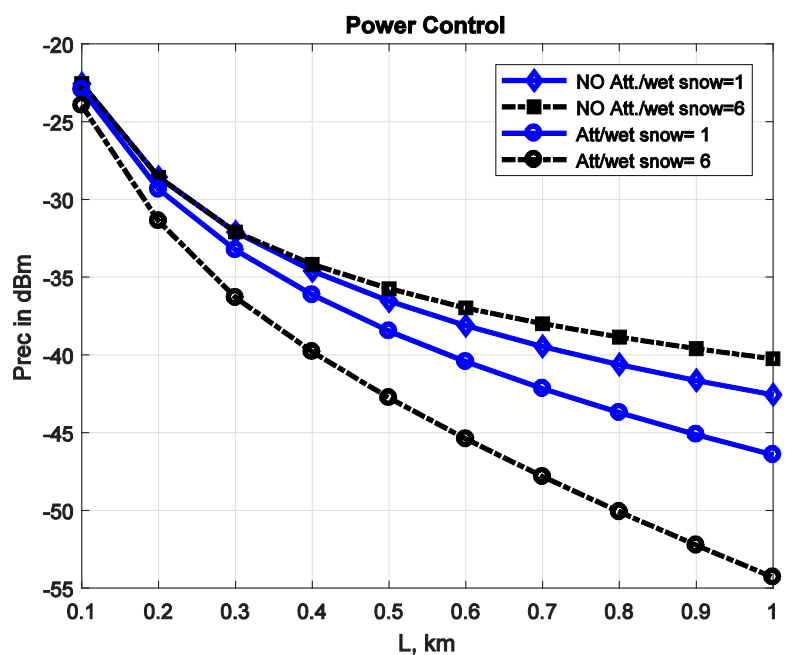

(b)

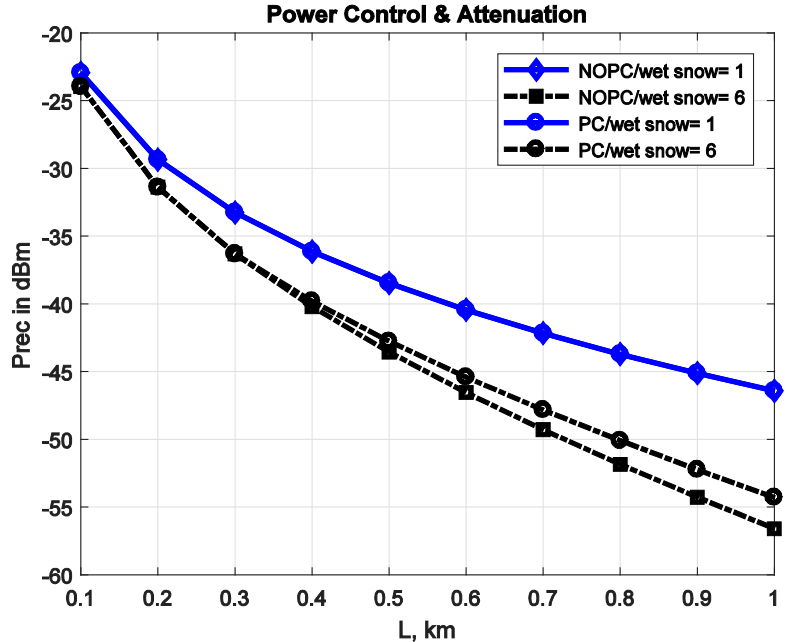

(c)

Figure 2. (a) Received power for wet snow without PC; (b) Received power for wet snow with PC; (c) Received power for wet snow. 


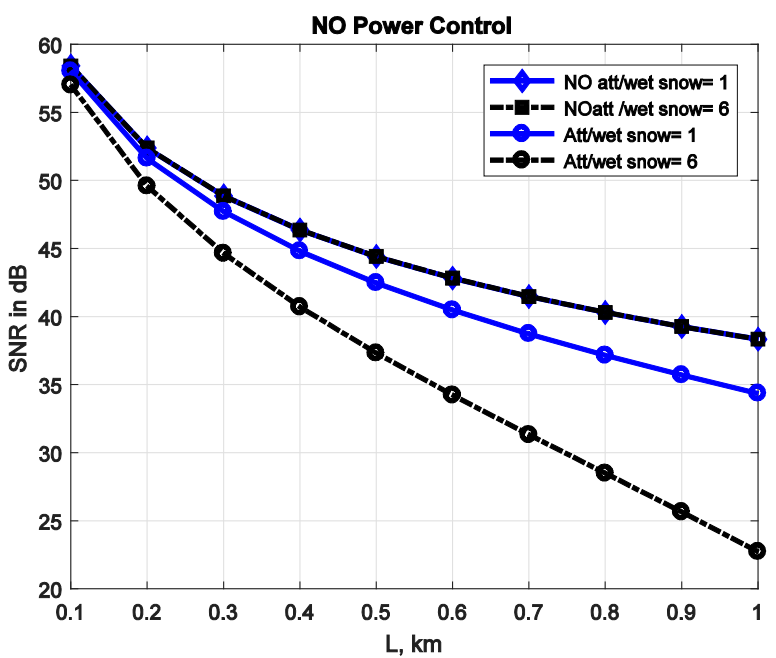

(a)

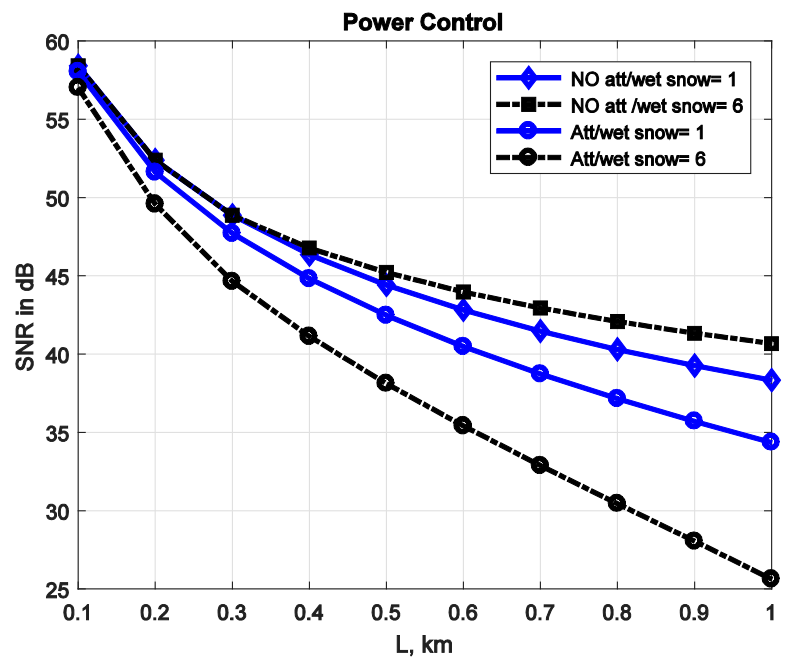

(b)

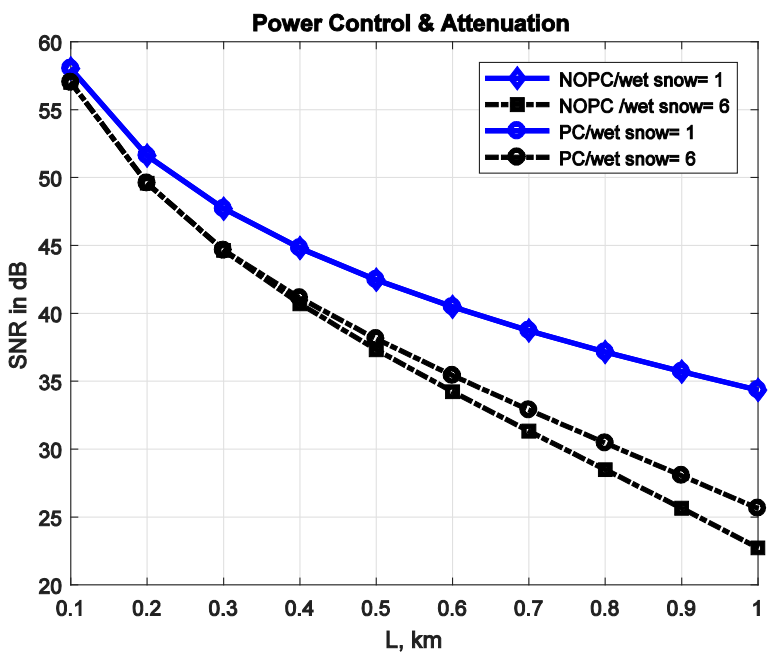

(c)

Figure 3. (a) SNR without PC for wet snow; (b) SNR with PC for wet snow; (c) SNR for wet snow. 
reaches $3 \mathrm{~dB}$ at $L=1 \mathrm{~km}$. In Figure 4 , the effect of PC on the BER for OOK modulation was investigated. At a link distance of $1 \mathrm{~km}$, the BER for a snow rate of $6 \mathrm{~mm} / \mathrm{him}$ proves from $9 \times 10^{-3}$ to $6 \times 10^{-3}$. The BER for a low snow rate is better than that for a higher snow rate. In Figure 5 we compared the BER for OOK modulation versus 16-PPM modulation for a snow rate that equals $6 \mathrm{~mm} / \mathrm{h}$. The PC improves the BER for both16-PPM and OOK modulation, especially at a link distance larger than $0.6 \mathrm{~km}$. The performance of PPM is better than that of OOK modulation.

Figure 6 shows the SNR for dry snow at rates of $1 \mathrm{~mm} / \mathrm{h}$ and $6 \mathrm{~mm} / \mathrm{h}$. The PC has no effect on the SNR for the low snow rate, but at a high snow rate, the PC improves the SNR slightly. The dry snow has more attenuation than the wet snow. In Figure 7, we show the effect of PC with OOK modulation for dry snow

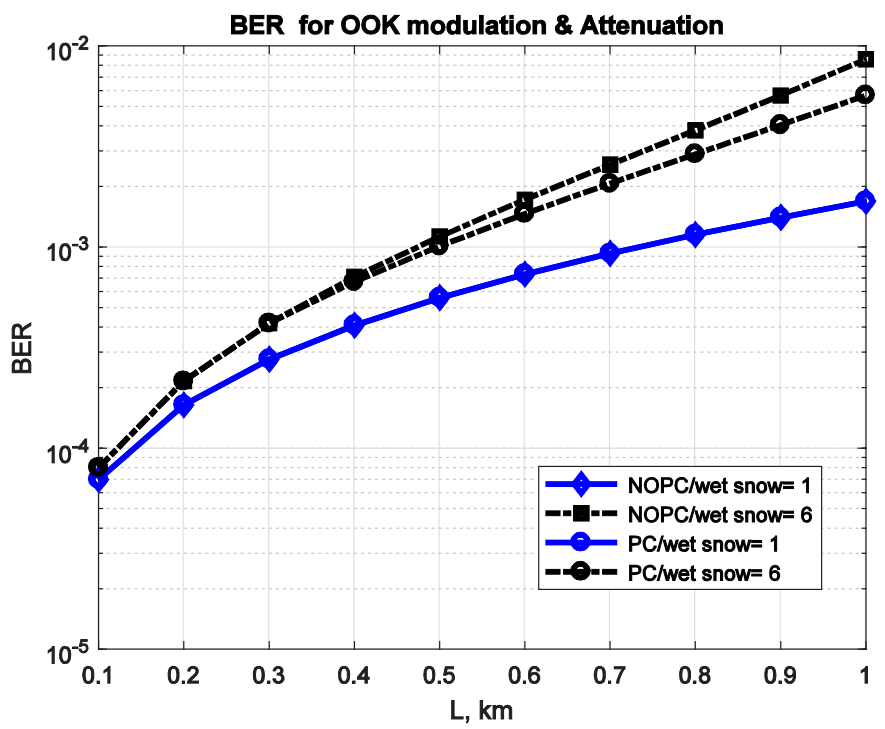

Figure 4. BER for OOK modulation.

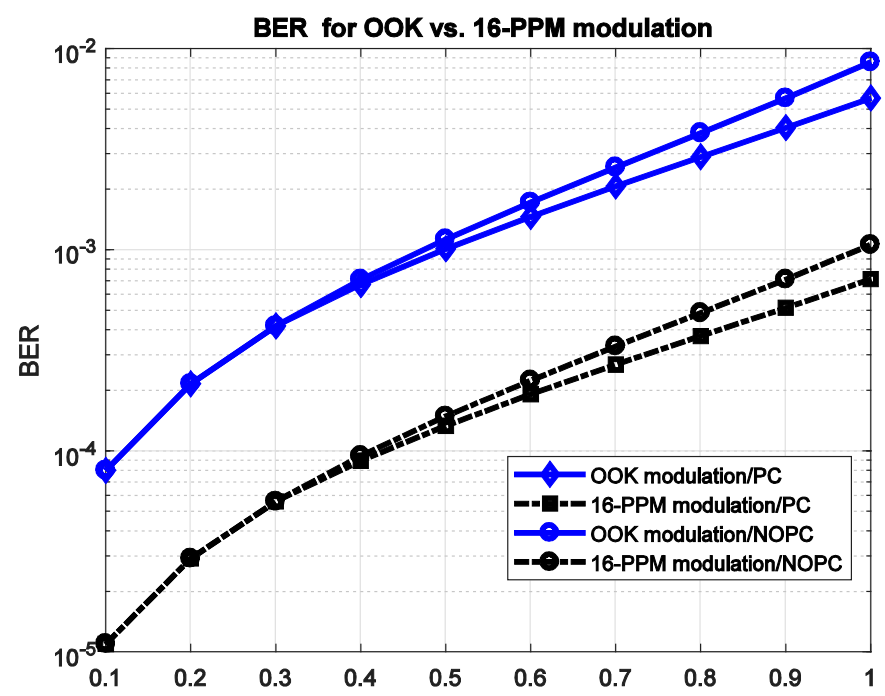

Figure 5. BER for OOK and PPM modulation. 


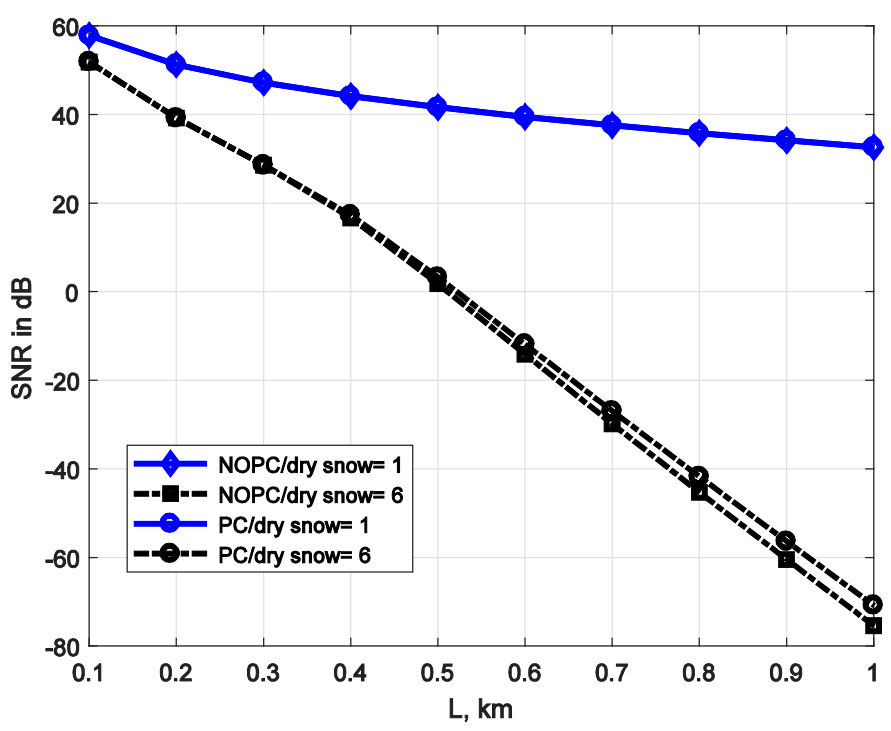

Figure 6. SNR for dry snow.

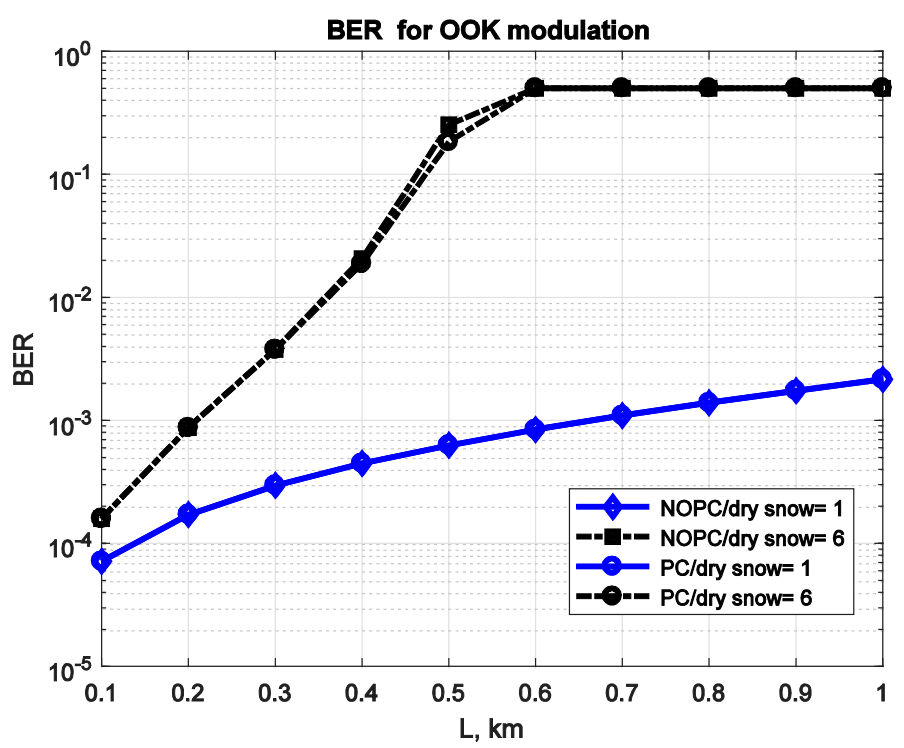

Figure 7. BER for OOK modulation with dry snow.

at snow rates of $1 \mathrm{~mm} / \mathrm{h}$ and $6 \mathrm{~mm} / \mathrm{h}$. The improvement in the BER with PC for the high snow rate is not significant, and no effect was shown for the low snow rate. In Figure 8, we show the effect of PC step size with OOK modulation for wet snow using a snow rate of $6 \mathrm{~mm} / \mathrm{h}$. For the PC, we use three-step sizes of 1 , 5 , and $10 \mathrm{mw}$. As shown in the figure, increasing the step size will improve the BER. In Figure 9, we show that PC improves the received power under rain attenuation by $1 \mathrm{dBm}$ for both rain rates at $L=1 \mathrm{~km}$. Also, Figure 10 shows the improvement in the SNR with PC for both rain rates. In Figure 11, the BER for OOK modulation under rain attenuation is shown, with an improvement from $3.6 \times 10^{-3}$ to $2.6 \times 10^{-3}$ at $L=1 \mathrm{~km}$. Figure 12 shows that 16 -PPM outperforms the OOK modulation. 


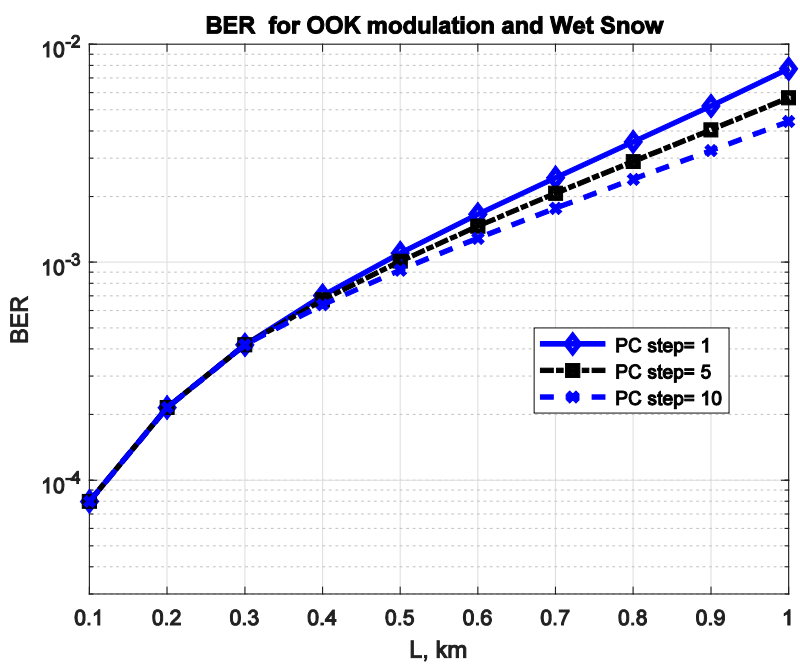

Figure 8. BER for OOK modulation with different PC step size for wet snow.

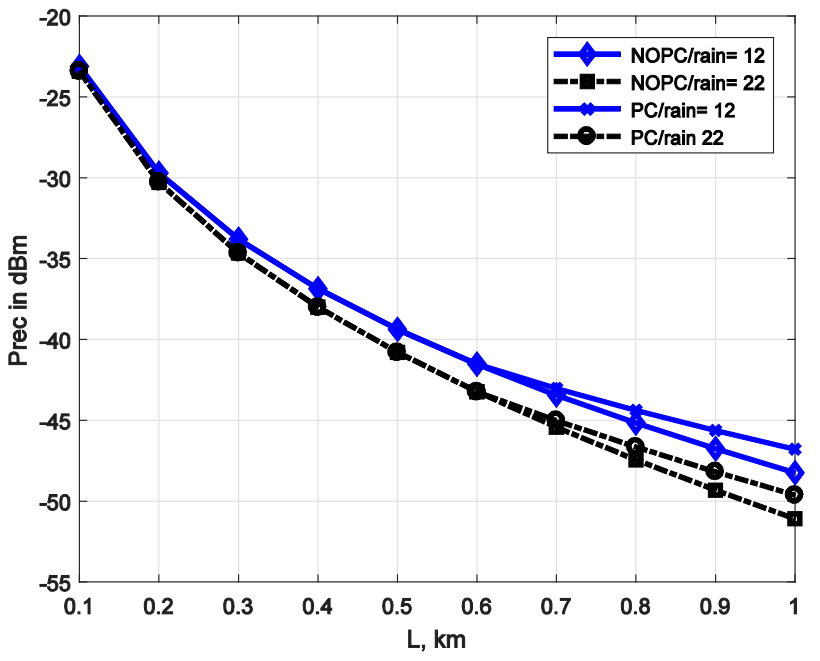

Figure 9. Received power with rain.

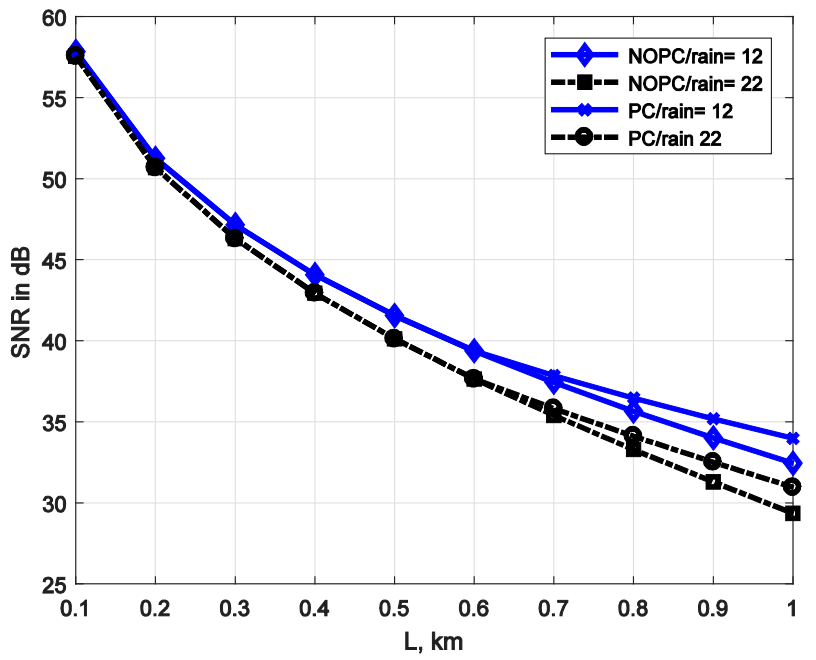

Figure 10. SNR with rain. 


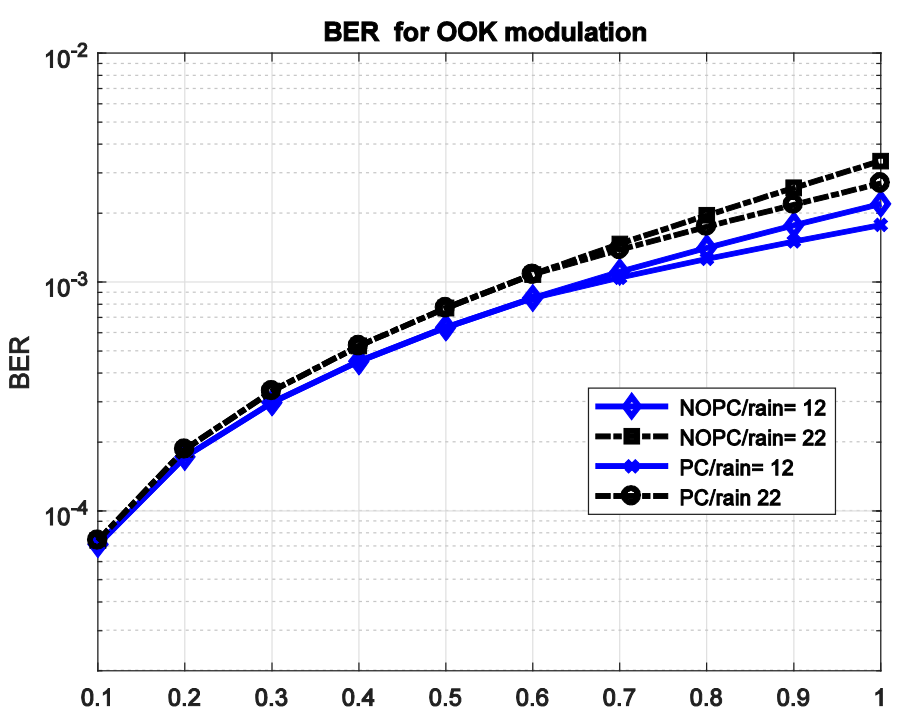

Figure 11. BER for OOK modulation with rain.

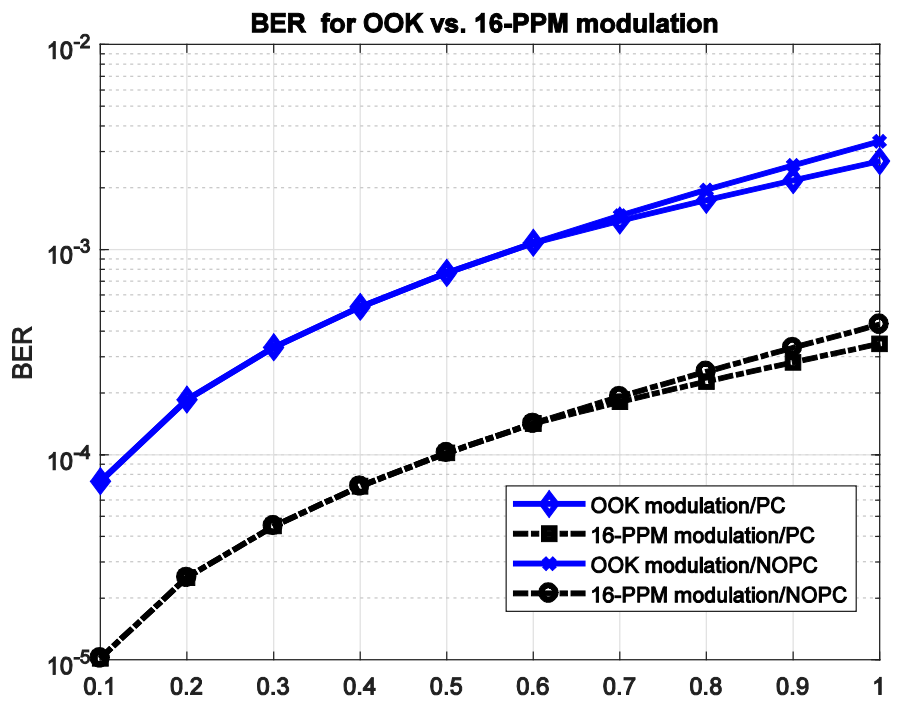

Figure 12. BER for OOK and PPM modulation with rain.

\section{Conclusion}

The FSO communications system is an evolving technology that promises to relieve the bottleneck at the last mile of bandwidth. Weather conditions such as snow and rain will severely attenuate the channel link and degrade the system's performance, however. Different adaptation scenarios have been suggested to be used in FSO communications, and one of them is transmitter PC. In this paper, we investigated the transmitter PC effect on the BER for OOK modulation and PPM during snow and rain attenuation. Results show that PC can improve the BER with high rates of wet snowfall, but it has no effect on the performance of FSO communications with dry snowfall. PC also improves the channel link and BER during high rates of rainfall. Finally, the BER for PPM is better than that for OOK modulation. 


\section{Conflicts of Interest}

The authors declare no conflicts of interest regarding the publication of this paper.

\section{References}

[1] Kim, I.I. and Eric, K. (2002) Availability of Free Space Optics (FSO) and Hybrid FSO/RF Systems. Optical Access, Incorporated, San Diego.

[2] Zhu, X.M. and Kahn, J.M. (2002) Free-Space Optical Communication through Atmospheric Turbulence Channels. IEEE Transaction on Communication, 50, 1293-1300. https://doi.org/10.1109/TCOMM.2002.800829

[3] Mazin, A. (2013) Transmission of Optical Signals for Wireless Communications under Snow Attenuation Effect. AIJRSTEM, September 2013, 15-21

[4] Hassan, N.B. and Matinfar, M.D. (2014) On the Implementation Aspects of Adaptive Power Control Algorithms in Free-Space Optical Communications. 2014 Iran Workshop on Communication and Information Theory (IWCIT), Tehran, 7-8 May 2014, 1-5.

[5] Salamah, S., Alsubaie, M.A., Alnaser, M.J. and Mahmoud, O. (2016) Free Space Optical Communications Performance under the Effect of Rain Attenuation in Canada. International Journal of Engineering Research and Applications, 6, 95-98.

[6] Kaushal, H. and Kaddoum, G. (2017) Optical Communication in Space: Challenges and Mitigation Techniques. IEEE Communications Surveys \& Tutorials, 19, 57-96.

[7] Nadeem, F., Leitgeb, E. and Awan, M.S. (2009) Comparing the Snow Effects on Hybrid Network Using Optical Wireless and GHz Links. 2009 International Workshop on Satellite and Space Communications, Tuscany, 9-11 September 2009, 171-175.

[8] Marshall, J.S. and Palmer, W.M. (1948) The Distribution of Raindrops with Size. Journal of Meteorology, 5, 165-166. https://doi.org/10.1175/1520-0469(1948)005<0165:TDORWS >2.0.CO;2

[9] Zhang, W. and Moayeri, N. (2011) Power-Law Parameters of Rain Specific Attenuation.

[10] ITU (2007) Prediction Methods Required for the Design for Terrestrial Free-Space Optical Links. Recommendation ITU-R P.1814.

[11] ITU (1994) Characteristics of Perception for Propagation Modeling. Recommendation ITU-R PN.837-1.

[12] Crane, R.K. and Robinson, P.C. (1997) ACTS Propagation Experiment: Rain-Rate Distribution Observations and Prediction Model Comparisons. Proceedings of the IEEE, 85, 946-958. https://doi.org/10.1109/5.598417

[13] Carbonneau, T.H. and Wisely, D.R. (1998) Opportunities and Challenges for Optical Wireless. SPIE Conference on Optical Wireless Communication, Wash, 119-128.

[14] Salamah, S., Falconer, D.D. and Yanikomeroglue, H. (2000) Transmit Power Control in Fixed Cellular Broadband Wireless Systems. WCNC, Chicago, 23-28 September 2000, 624-628.

[15] Elganimi, T.Y. (2013) Performance Comparison between OOK, PPM and PAM Modulation Schemes for Free Space Optical (FSO) Communication Systems: Analytical Study. International Journal of Computer Applications, 79, 22-27. 